\title{
Investigation on Material Removal Rate and Surface Finish in Electrical Discharge Machining of AA 6061-B 4 C Composite Material
}

\author{
N.Ethiraj ${ }^{1, *}$, T.Sivabalan ${ }^{2}$, Saibal Chatterjee ${ }^{3}$, Seeramsetti Mahesh $^{4}$, Mrityunjay $^{2}$ \\ Kumar Chandravanshi ${ }^{5}$ \\ ${ }^{1}$ Professor, Department of Mechanical Engineering, Dr.M.G.R Educational and \\ Research Institute, Chennai-600 095, India. \\ ${ }^{2}$ Assistant Professor, Department of Mechanical Engineering, Dr.M.G.R \\ Educational and Research Institute, Chennai-600 095, India. \\ ${ }^{3,4,5}$ Undergraduate Student, Department of Mechanical Engineering, Dr.M.G.R \\ Educational and Research Institute, Chennai-600 095, India. \\ 1ethiraj.mech@drmgrdu.ac.in, ${ }^{2}$ sivabalan.mech@drmgrdu.ac.in, ${ }^{3}$ saibalchatterjee1996@gmail.com, \\ ${ }^{4}$ maheshseeramsetti@gmail.com, ${ }^{5}$ mchandravanshi077@gmail.com
}

\begin{abstract}
One of the non-conventional techniques of metal removal manufacturing processes is electrical discharge machining (EDM). The objective of this paper is to prepare a composite material consisting of a matrix of Aluminium AA 6061 alloy and Boron carbide $\left(\mathrm{B}_{4} \mathrm{C}\right)$ as reinforcement and investigate the output responses, the material removal rate, the quality of the surface formed and overcut during EDM process. The process parameters discharge current, Pulse on time and Duty cycle along with the weight $\%$ of $\mathrm{B}_{4} \mathrm{C}$ are considered for investigation to investigate the output responses such as material removal rate, surface roughness and overcut.From the experimental results, it is observed that the weight $\%$ of reinforcement has more influence on the material removal rate. The parameters discharge current and pulse-on-time plays an important role in reducing the surface roughness and overcut. Microstructural study helps in understanding the effect of process parameters on the output responses.
\end{abstract}

Keywords:Electrical discharge machining. Aluminium matrix. Boron carbide. Composite material

\section{Introduction}

Electrical discharge machining is one of the non-traditional machining processes in which the spark produced between the two electrodes generates heat to remove the material[1]. The mechanisms of metal removal rate (MRR)in EDM of carbon fiber reinforced polymers have been investigated[2]. It was found to be the most significant parameters in EDM of Alminium- ${ }_{4} \mathrm{C}$-Graphite composites are current and pulse on time[3]. EDM process is also used to remove the burrs produced during drilling operation of carbon fiber reinforced plastics composites. This method is very effective in removing the burrs without damaging the hole due to the proper maintenance of spark gap[4]. Since EDM of electrically nonconductive ceramic materials is not possible, a non-conventional EDM method was employed to surface treat Zirconia to improve the Zirconia-Resin bonding for dental application. It was concluded from their experiments that the surface treatment by EDM increases the shear bond strength when compared with other surface treatment processes[5]. For improving the material removal rate the researchers have adopted the following methods: (a) optimization of process parameters was carried out in EDM of

*Corresponding Author: Dr.N.Ethiraj 
cryo-treated NiTi alloy [6]; (b)using a rotating tool for machining AISI D3 steel [7] and

(c) using a filter to improve the gap voltage [19].

Most of the investigations carried out on EDM of composite materials containing aluminium/ its alloy as matrix material with different reinforcement like Silicon Carbide [9,14],Cenosphere fly ash [10], Alumina [12,16,18], Zirconium Boride and Titanium Boride [15]. The machinability characteristics of Silicon Carbide based composites with Titanium-Niobium carbide addditives was studied and concluded that, even though the machinability of the material is improved, there is a need for surface treatment to get a good surface finish [8]. Investigation on EDM machinability of Zirconia-Titanium Carbide based ceramic nanocomposites revealed that both the electrical conductivity of the material and machinability performance in EDM have reduced due to the nickel, cobalt and iron addition [11]. The effect of different dielectrics on the performance of EDM was studied in machining aluminium 6061-T6 alloy and found that dielectric kerosene is preferable in comparison with distilled water [17]. The influence of reinforcement particle size on the EDM machinability was studied using zirconia toughened alumina (ZTA) with TiC as reinforcement and arrived a conclusion that the electrical conductivity increases with the decrease in particle size and hence the machinability in EDM has increased significantly [20]. In general, some of the major problems encountered in EDM are Wear and breakage of the tool and recast layer [13].

The volume of metal removed per discharge of single pulse was calculated by measuring the number of discharges and MRR at different pulse shapes to understand the reason for improvement in MRR [21]. A gap-active EDM (GA-EDM), a concept based on the principle of operation of parallel plate capacitor, was used to evaluate the performance of EDM of Ti6Al4V titanium alloy using copper electrode [22]. Low MRR and better surface finish was observed from their investigation in all discharge levels. Also, it was reported by Shirsendu Das et al., 2021 [23] that no observation is available till date regarding the measurable responses such asmaterial removal rate, surface roughness and micro-hardness during EDM of AA6092/17.5 SiCp-T6 material which is very widely used in defense and aviation industries. A Study was carried out to optimize the process parameters in EDM of Al6061/SiC composite using different electrodes such as copper and brass. It was concluded from the investigation that the increased MRR was observed while using the brass electrode when compared with the copper electrode [24].In order to improve the MRR and surface roughness of the EDM process, low frequency vibration was used in conjunction with EDM process and found that the MRR was improved due to the controlled spark-energy and the effect of vibration frequency has more influence on the quality characteristics of the machined surfaces[25].

From the literature survey, it is noted that the performance of EDM of different aluminium matrix based composites with different reinforcements are researched in the past and sufficient information is available in this regard. Among these investigations, the use of boron carbide as reinforcement is very little and more study on this aspect need to be made. The aim of this research work is to investigate the MRR and surface finish during EDM of aluminium based composite with Boron carbide $\left(\mathrm{B}_{4} \mathrm{C}\right)$ as reinforcement.

\section{Experimentation}

\subsection{Preparation of Composite Material}

Aluminium 6061 alloy is one of the most extensively used materials among the 6000 series due to its properties such as high strength, good workability, good corrosion resistance etc. Boron carbide is one of the promising ceramic materials due to its attractive properties like low density, high strength and extremely high hardness (the third hardest 
material after diamond and boron nitride) and good chemical stability. It has got good nuclear properties like neutron absorption capability and stability to ionizing radiation. The composite material used for this investigation consists of $\mathrm{Al}$ alloy 6061 as matrix and $\mathrm{B}_{4} \mathrm{C}$ as reinforcement.

Aluminium alloy 6061 rod of $40 \mathrm{~mm}$ diameter was supplied by Bhandari Metal Trading Corporation and was cut into small pieces for melting. Boron carbide having 220 mesh size was purchased from Speedfam (India) Pvt.Ltd.Preheating of boron carbide and AA6061 aluminium alloy was done in theIndfurr make high temperature muffle furnace. Stir casting process was used for fabricating the composite material, in which both the matrix and the reinforcement materials are thoroughly mixed in a graphite crucible by a stainless stirrer with three blades. The boron carbide powder was added with the melted matrix material and vigorous stirring action was carried out for 5-6 min at a stirring speed of $550 \mathrm{rpm}$ to uniformly disperse the reinforcement material. Then, the mixture was poured into the die to make the plates of $100 \mathrm{X} 100 \mathrm{X} 10 \mathrm{~mm}$ size. Fig.1 shows the matrix and reinforcement material used and the method of fabricating the composite plates by stir casting process.

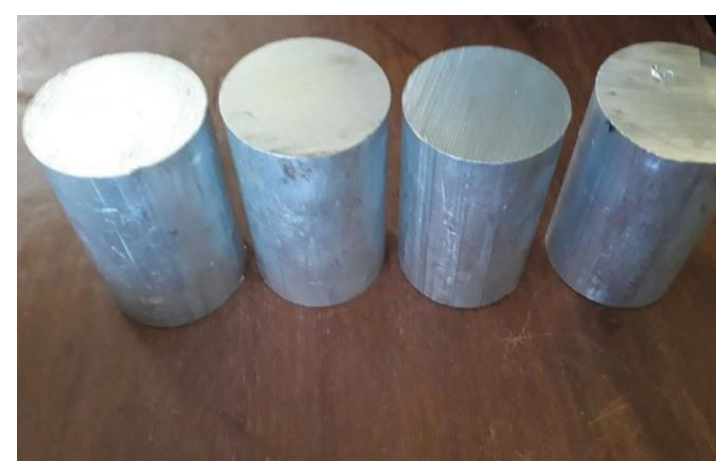

a)Aluminium 6061 rods (Matrix)

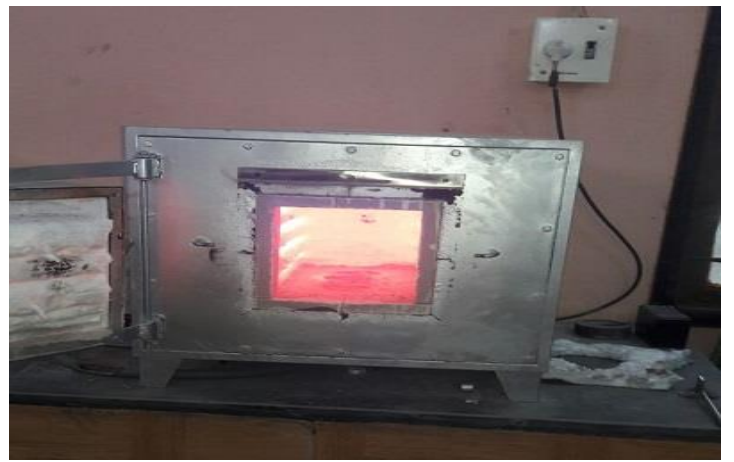

c)Muffle Furnace

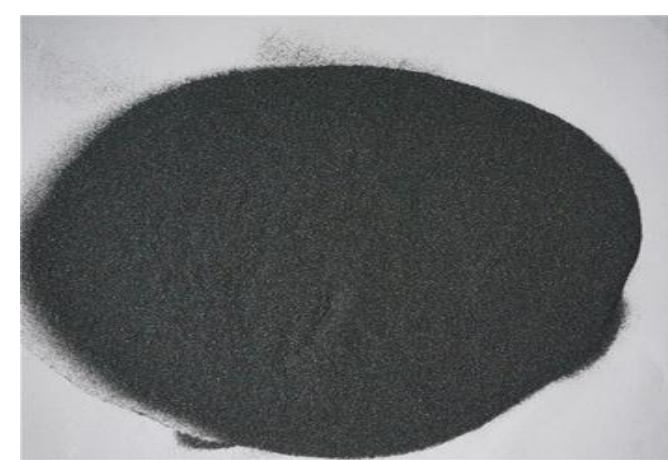

b)Boron Carbide Powder (Reinforcement)

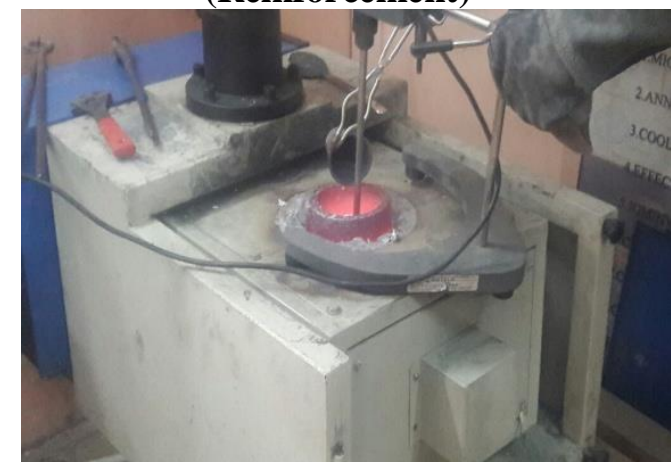

d)Stir Casting Process

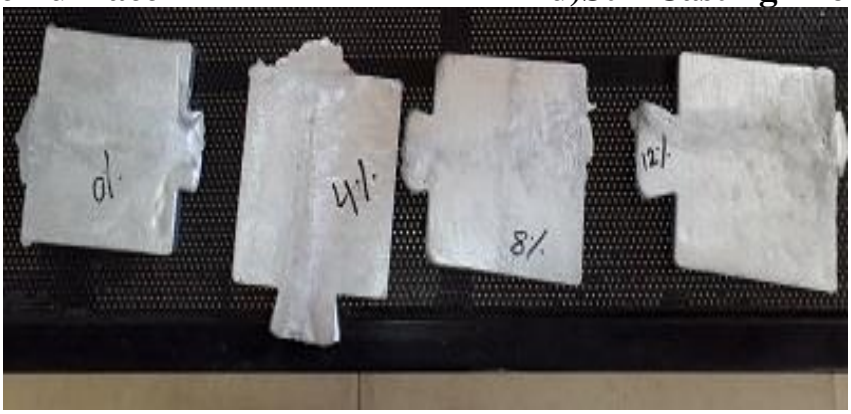

e)Fabricated $\mathrm{Al}-\mathrm{B}_{4} \mathrm{C}$ Composite Plates Figure 1. Preparation of Composite material 
The composite plates of three samples each are made with AA6061 without reinforcement, with reinforcement of $4 \%, 8 \%$ and $12 \%$ of reinforcement.

\subsection{Process Parameters}

For the present investigation, the discharge current (I), Pulse on time $\left(\mathrm{T}_{\text {on }}\right)$ and duty cycle (\%) are considered as input process parameters. Four levels of process parameters are selected based on the literature survey made. The process parameters used and their different levels are shown in Table $\mathbf{1 .}$

Table 1. Process Parameters and its Levels

\begin{tabular}{|c|r|r|r|r|}
\hline \multirow{2}{*}{ Process Parameters } & \multicolumn{4}{|c|}{ Level } \\
\cline { 2 - 5 } & $\mathbf{1}$ & $\mathbf{2}$ & $\mathbf{3}$ & $\mathbf{4}$ \\
\hline Discharge Current in A & 12 & 16 & 20 & 24 \\
\hline Pulse on time in $\mu \mathrm{s}$ & 35 & 55 & 75 & 95 \\
\hline Duty cycle in \% & 60 & 70 & 80 & 90 \\
\hline
\end{tabular}

The number of EDM experiments to be conducted and the level of input process parameters are decided by design of experiments(DOE). Taguchi method, sometimes known as robust design method, involving the orthogonal arrays is used for identifying the process parameters and its level for conducting the experiments. Since there are four factors (including the wt $\%$ of reinforcement) with four levels each, $\mathrm{L}_{16}$ orthogonal array was selected using the statistical software MINITAB 17.

\subsection{Experimental Procedure}

Electrical discharge machining processes are carried out in CJ-341 ZNC machine. The tool material used is the copper with the diameter of $19.6 \mathrm{~mm}$ and marketable grade EDM oil (specific gravity $=0.763$, freezing point $=94^{\circ} \mathrm{C}$ ) is used as an electrolyte. The process parameters are according to the values obtained from the Taguchi's method. During all the experiments, the voltage is kept as constant at $40 \mathrm{~V}$. The machine used for experimentation is shown in Fig. 2.

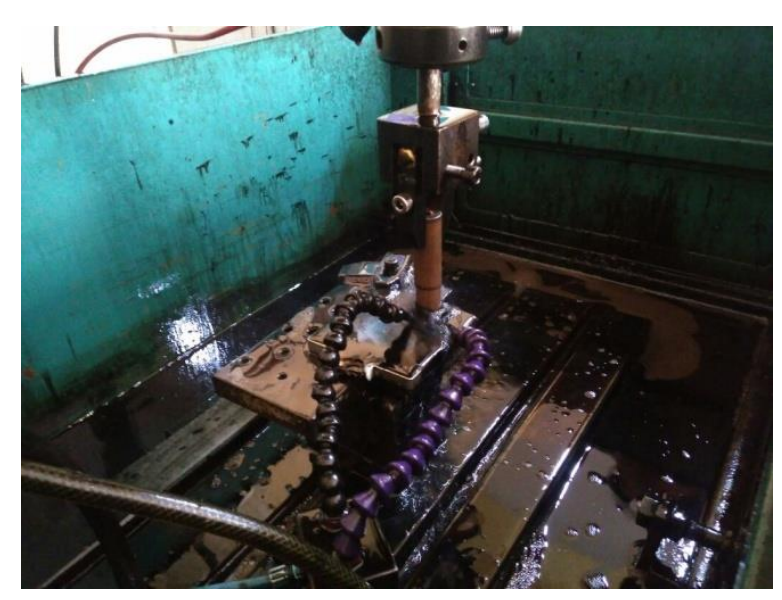

Figure 2. EDM Machine 
The four circular cavities are made in the fabricated composite plates by EDM process using each set ofprocess parameters is shown in Figure 3. The diameter and the depth of the cavity is measured by vernier caliper and depth gauge for calculating the material removal rate (MRR) using the following equation (1).

$$
\mathrm{MRR}=\frac{\text { Volumeofthecavity }}{\text { Machiningtime }}=\frac{\pi R^{2} L}{t}
$$

Where $\mathrm{R}$ is the radius and $\mathrm{L}$ is the depth of the machined cavity. Taguchi method of Larger the better $(\mathrm{LB})$ criteria is used for analyzing the MRR. The $\mathrm{S} / \mathrm{N}$ ratios for MRR are calculated using the equation (2).

$$
\text { LB: } \eta=-10 \log \left[\frac{1}{n} \sum_{i=1}^{n} y_{i}^{-2}\right]
$$

Where $\eta$ denotes the $\mathrm{S} / \mathrm{N}$ ratios calculated from observed values, $\mathrm{y}_{\mathrm{i}}$ represents the experimentally observed value of the $\mathrm{i}^{\text {th }}$ experiment and $\mathrm{n}$ is the repeated number of each experiment in L-16 orthogonal array. Smaller the better(SB) criteria of Taguchi method is used for the analysis of surface roughness (Ra values) and overcut. The equation (3) is used for calculating the $\mathrm{S} / \mathrm{N}$ ratios of surface roughness and overcut.

$$
\mathrm{SB}: \eta=-10 \log \left[\frac{1}{n} \sum_{i=1}^{n} y_{i}^{2}\right]
$$

The cavities made in EDM using different process parameters are presented in the Fig.3

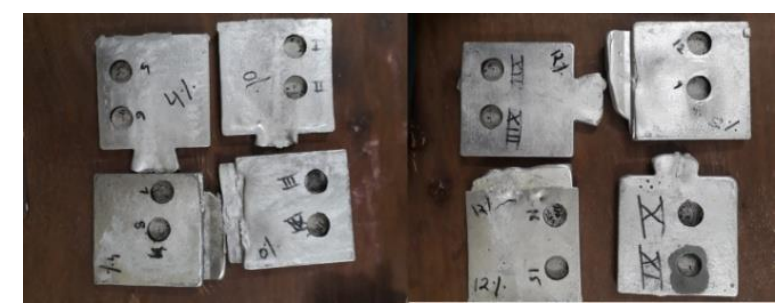

Figure 3. Circular Cavities machined by EDM.

The surface roughness of the machined surfaces is measured using KOSAKA SEF 3500 D Profilo-meter and the microstructure images are taken in the TESCAN VEGA3 scanning electron microscope (SEM). The cavity machined in EDM process is always more than the size of electrode used to machine. The difference between the size of the cavity and the size of the electrode is known as overcut. For this purpose, the measurements are made using tool maker's microscope and outside micrometer.

\section{Results and Discussion}

The measured values of MRR, overcut and Surface roughness for the 16 experiments are shown in Appendix 1. These measured values are fed into the software MINITAB 17 for analyzing the output responses based on the selected criteria of Taguchi method.

\subsection{Effect of Process Parameters on MRR}

The graphs indicating the variation in MRR $\left(\mathrm{mm}^{3} / \mathrm{min}\right)$, both mean and $\mathrm{S} / \mathrm{N}$ ratio, with respect to the input parameters are shown in Fig.4. From the figure 4(b), it is observed that the higher material removal rate is achieved within the experimented values in a composite material with $12 \%$ weight $\mathrm{B}_{4} \mathrm{C}$ when the $\mathrm{EDM}$ is done with the process parameters $20 \mathrm{~A}$ discharge current, $35 \mu$ s pulse on time and $90 \%$ duty cycle. Also, it is 
observed from the figure 4 (a) that the weight $\%$ of $\mathrm{B}_{4} \mathrm{C}$ in the composite has more effect on the material removal rate.

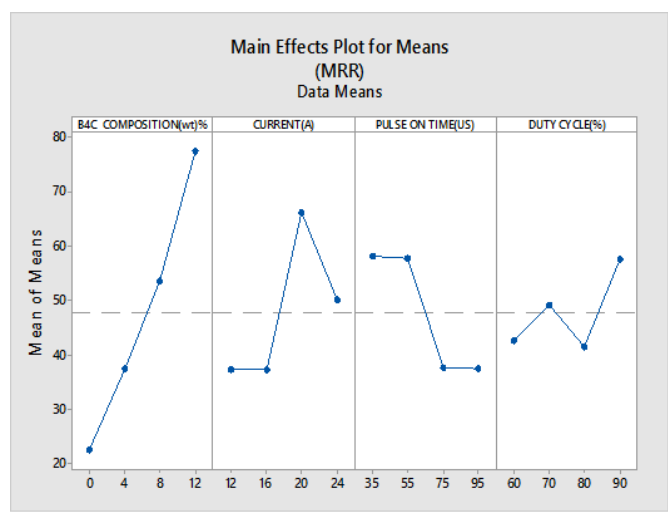

(a)

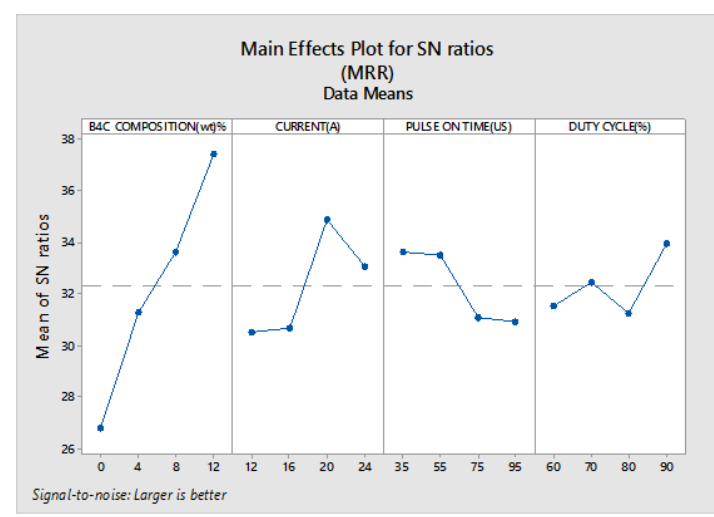

(b)

Figure 4. (a) Mean plot of $M R R\left(\mathrm{~mm}^{3} / \mathrm{min}\right)$; (b) $\mathrm{S} / \mathrm{N}$ ratio plot of MRR

\subsection{Effect of Process Parameters on Surface Roughness}

Fig.5 shows the variation in $\mathrm{Ra}(\mu \mathrm{m})$, both mean and $\mathrm{S} / \mathrm{N}$ ratio, with respect to the input parameters.From the figure 5(b), it is observed that the roughness of the machined surface is lower within the experimented values in a composite material with $12 \%$ weight $\mathrm{B}_{4} \mathrm{C}$ when the process parameters are $24 \mathrm{~A}$ discharge current, $55 \mu$ s pulse on time and $70 \%$ duty cycle. Also, it is observed from the figure 5(a) that the discharge current has more dominating effect on the roughness of the machined surface.

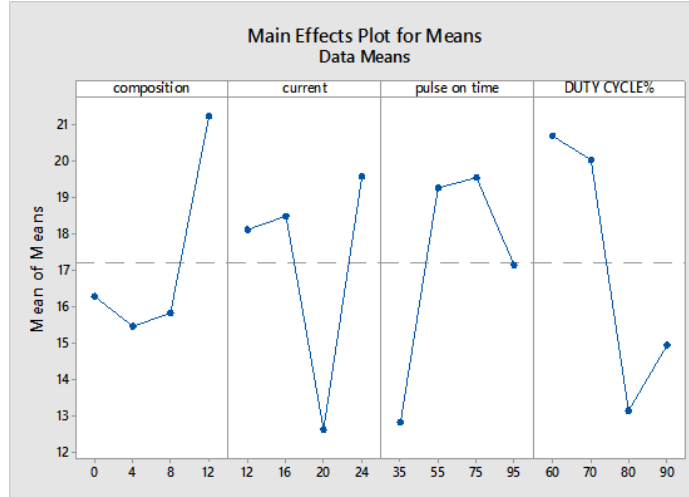

(a)

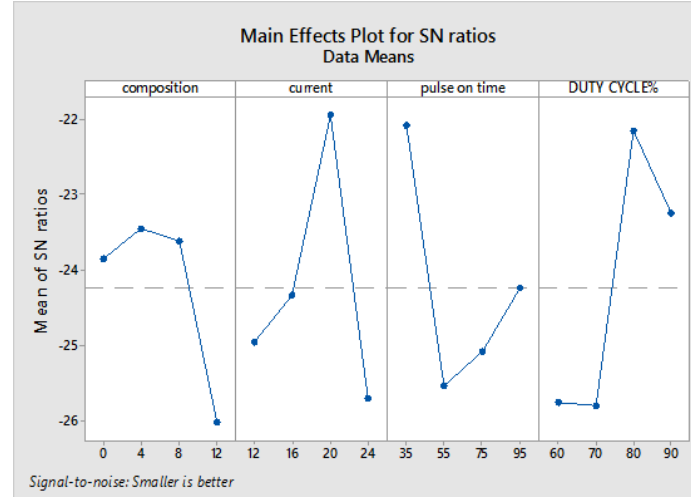

(b)

Figure 5. (a) Mean plot of surface roughness (Ra in $\mu \mathrm{m})$; (b) $\mathrm{S} / \mathrm{N}$ ratio plot of $\mathrm{Ra}$

\subsection{Effect of Process Parameters on overcut}

The variation in overcut, both mean and $\mathrm{S} / \mathrm{N}$ ratio, with respect to the input parameters is shown in Fig. 6. From the figure 6(b), it is noted that the overcut in the machined cavity is lower within the experimented values in a composite material with $12 \%$ weight $\mathrm{B}_{4} \mathrm{C}$ when the process parameters are $24 \mathrm{~A}$ discharge current, $95 \mu$ s pulse on time and $80 \%$ duty cycle. Also, it is observed from the figure 6 (a) that the $\%$ weight of $\mathrm{B}_{4} \mathrm{C}$ has more influencing effect on the overcut of the machined cavity.

Overall, the weight $\%$ of $\mathrm{B}_{4} \mathrm{C}$ plays a predominant role in output responses and the discharge current and pulse-on-timeare the next influencing parameter when compared with duty cycle. 
The discharge energy supplied in the zone of machining determines the material removal rate in the EDM process. Higher MRR is achieved at higher discharge energy because of melting and vapourization. In EDM process, the discharge current is directly proportional to the MRR. This may be because of the reason that the sparks produced at higher discharge current produces a higher temperature which increases the erosion of the material and hence higher MRR. In the same way, the increase of pulse-on-time increases the spark energy which in turn increases the MRR. But, beyond certain optimum value, the pulse-on-time cause more material removal and the time of flushing the removed material increases and MRR is decreased.

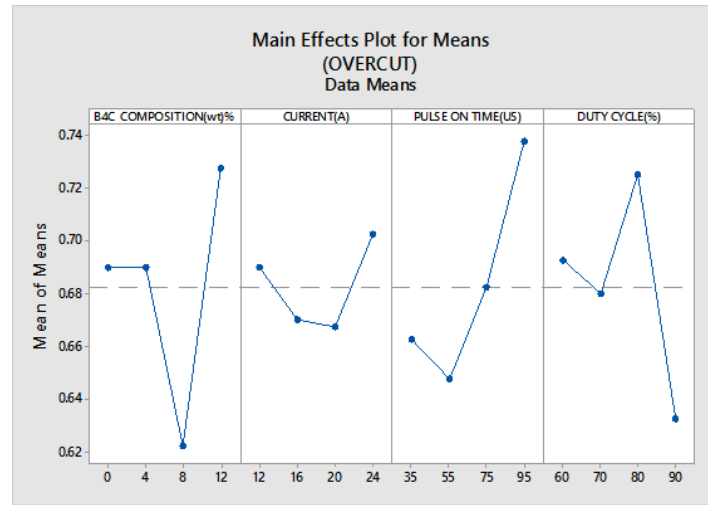

(a)

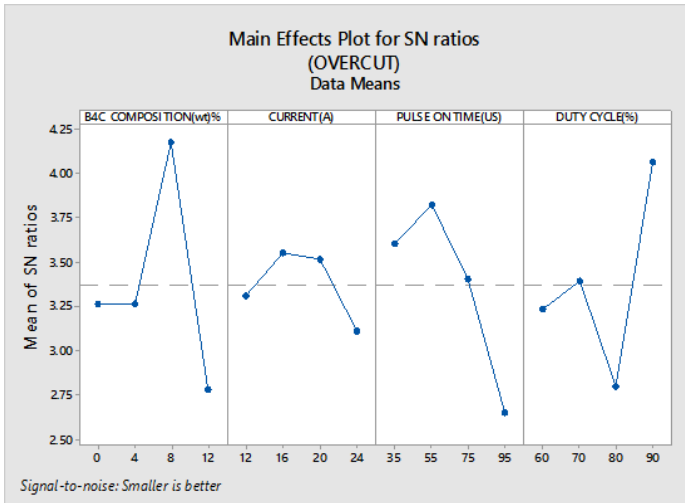

(b)

Figure 6. (a) Mean plot of overcut(mm); (b) S/N ratio plot of overcut

Usually, the increase in discharge current and pulse-on-time increases the surface roughness showing poor surface finish due to higher discharge energy produces a crater in the machined surface. Also, the resulting cratersare broader due to the longer time of sustaining sparks causing the more size. In order achieve a good surface finish and less overcut, it is better to maintain these parameters at low values. But, in present investigation, it is observed that the higher discharge current is responsible for the lower surface roughness when the pulse-on-time is lower and higher weight $\%$ of boron carbide. It may be due to the reason that some amount of higher discharge energy may be utilized for melting and vapourizing the higher $\%$ of reinforcement present in the composite material.

\subsection{Microstructural Study}

The SEM images of the unmachined and machined surfaces of AA 6061 without reinforcement is presented in Fig. 7 (a) \& (b).It is seen from figure 7(a) that there exist some pores and craters or pockets in the unmachined surface itself which might have been formed during stir casting process. It may be due to (i) the entrapment of gas while stirring; (ii) presence of water vapour on the particle surface; and (iii) occurrence of shrinkage during solidification. After machining, it is observed from the figure 7(b) that the craters and pores are elongated and the flow of materials is noticeable. The number of craters observed are lesser than that of the unmachined one and this may be due the packing of materials in the craters already available during flushing action. The images taken in SEM displaying the machined surface of AA 6061 with different weight $\%$ of $\mathrm{B}_{4} \mathrm{C}$ are shown in figure 8 (a-c).Lot of craters are noticed in all the machined surfaces of AA6061 with different $\%$ weight reinforcement and no elongation of craters due to 
machining also observed. It may be due to the dislodging of reinforcement particles from the matrix during machining leaving a crater. These dislodged reinforcement particles

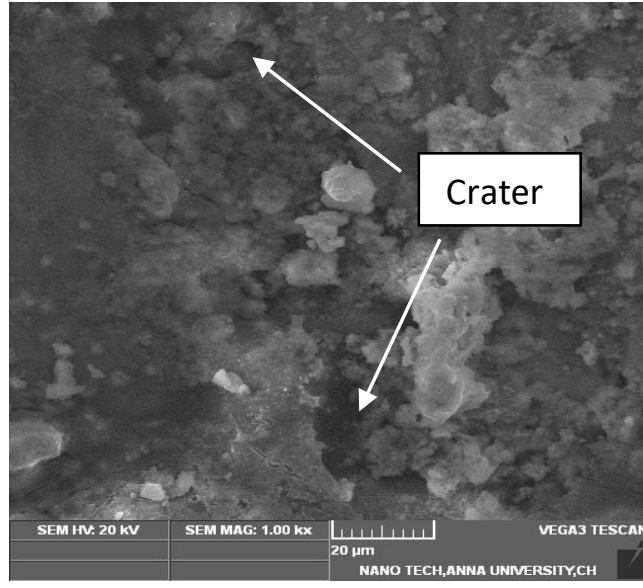

(a)

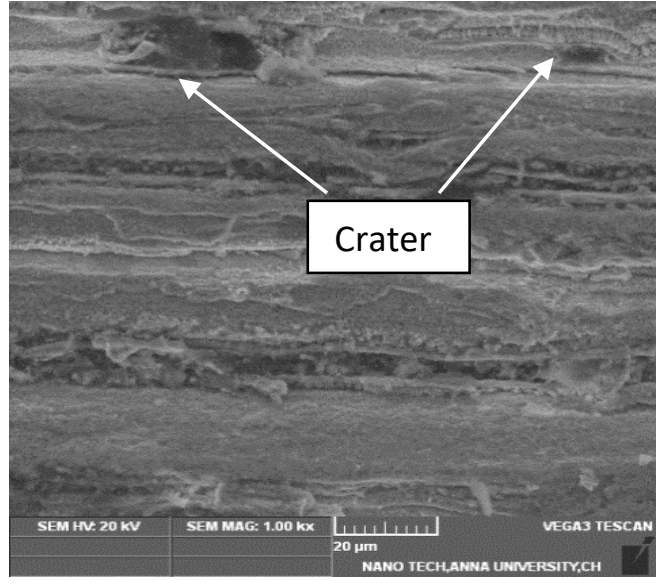

(b)

Figure 7. SEM image of $\mathrm{AA6061}$ without $\mathrm{B}_{4} \mathrm{C}$ a) before Machining; b) after Machining

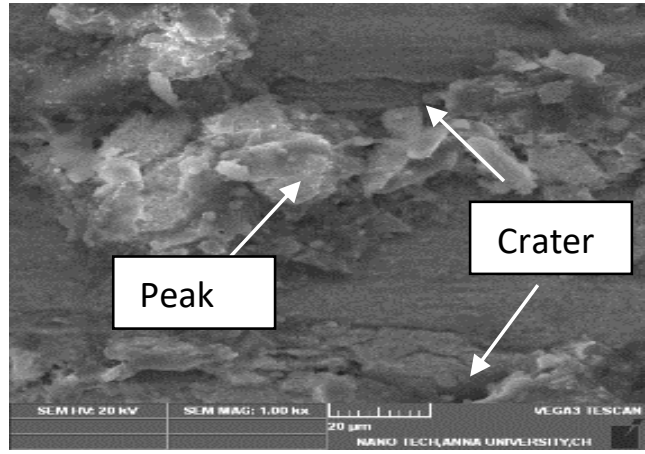

(a)

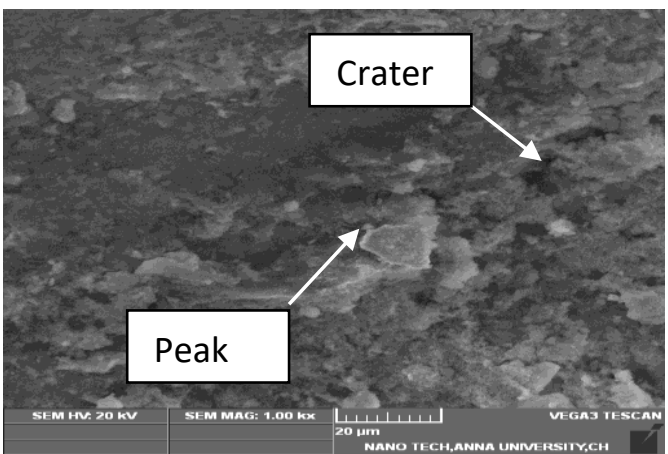

(b)

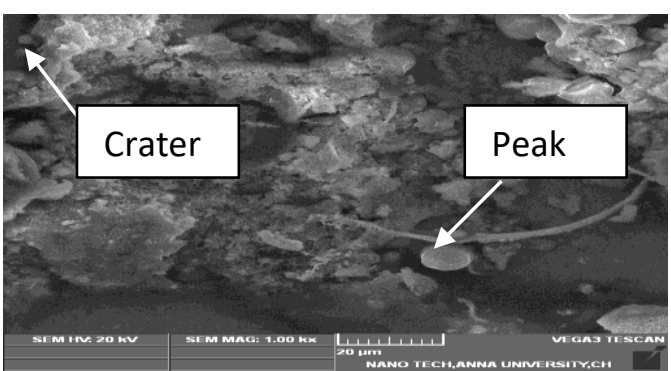

(c)

Figure 8. SEM image of AA6061 with $\mathrm{B}_{4} \mathrm{C}$ a) $4 \%$ b) $8 \%$ and c) $12 \%$ after machining

may entrapped in the newly formed layer during solidification which may affect the surface finish adversely. The larger value of discharge current andPulse-on-time, even though improves the MRR, increases the discharge energy and causes the crater size bigger. But, at the same time, the higher $\%$ of reinforcement particles oppose the applied electrical field which in turn reduces the discharge energy and the size of the crater is diminished. No surface cracks are noticed in all the captured SEM images. 


\section{Conclusion}

The AA $6061-\mathrm{B}_{4} \mathrm{C}$ composite material was fabricated using stir casting process and the electrical discharge machining was successfully carried out with different process parameters to study the effect of these parameters on the output responses such as MRR, surface roughness and overcut. From the investigation, the following conclusions are derived within the experimented parameters:

i) The higher percentage of reinforcement influences the MRR in EDM process. The discharge current and pulse-on-time help in improving the MRR.

ii) Beyond optimum value of the pulse-on-time, the MRR is reduced due to more material removal but more time is required to flush these materials.

iii) The current and the pulse-on time are the dominating factors in improving the finish of the machined surface. From the experimentation, it is found that $17 \%$ reduction in surface roughness.

iv) The discharge current and pulse-on-time must be kept at low values to get better surface finish and less overcut. But the higher percentage of reinforcement takes up more discharge energy for melting and hence the higher values may be used.

\section{Appendix 1 - Experimental Results}

\begin{tabular}{|c|c|c|c|c|c|c|c|c|c|c|}
\hline $\begin{array}{c}\text { Run } \\
\mathbf{S}\end{array}$ & $\begin{array}{c}\mathbf{B}_{\mathbf{4}} \mathbf{C} \\
(\mathbf{w t} \\
\mathbf{\%})\end{array}$ & $\begin{array}{c}\text { Current( } \\
\mathbf{A})\end{array}$ & $\begin{array}{c}\text { Pulse } \\
\mathbf{\text { on }} \\
\mathbf{t i m e} \\
(\boldsymbol{\mu s})\end{array}$ & $\begin{array}{c}\text { Duty } \\
\mathbf{c y c l}(\mathbf{\%})\end{array}$ & $\begin{array}{c}\text { MRR } \\
\left(\mathbf{m m}^{3} /\right. \\
\mathbf{m i n})\end{array}$ & $\begin{array}{c}\text { S/N Ratio } \\
(\mathbf{M R R})\end{array}$ & $\begin{array}{c}\text { Overcut } \\
(\mathbf{m m})\end{array}$ & $\begin{array}{c}\text { S/N ratio } \\
(\mathbf{o v e r c u t})\end{array}$ & $\begin{array}{c}\text { Ra } \\
(\boldsymbol{\mu m})\end{array}$ & $\begin{array}{c}\text { S/N } \\
\text { ratio } \\
(\mathbf{R a})\end{array}$ \\
\hline 1 & 0 & 12 & 35 & 60 & 15.55 & 23.83461 & 0.71 & 2.974833 & 14.09 & -22.9782 \\
\hline 2 & 0 & 16 & 55 & 70 & 20.44 & 26.20962 & 0.59 & 4.58296 & 21.6 & -26.6891 \\
\hline 3 & 0 & 20 & 75 & 80 & 25.53 & 28.14102 & 0.69 & 3.223018 & 9.91 & -19.9215 \\
\hline 4 & 0 & 24 & 95 & 90 & 28.34 & 29.048 & 0.77 & 2.270185 & 19.49 & -25.7962 \\
\hline 5 & 4 & 12 & 55 & 80 & 34.88 & 30.85153 & 0.76 & 2.383728 & 17.53 & -24.8756 \\
\hline 6 & 4 & 16 & 35 & 90 & 48.27 & 33.67355 & 0.58 & 4.73144 & 10 & -20 \\
\hline 7 & 4 & 20 & 95 & 60 & 37.31 & 31.4365 & 0.69 & 3.223018 & 13.48 & -22.5938 \\
\hline 8 & 4 & 24 & 75 & 70 & 29.05 & 29.26292 & 0.73 & 2.733543 & 20.77 & -26.3487 \\
\hline 9 & 8 & 12 & 75 & 90 & 39.77 & 31.99111 & 0.53 & 5.514483 & 16 & -24.0824 \\
\hline 10 & 8 & 16 & 95 & 80 & 24.64 & 27.83281 & 0.73 & 2.733543 & 10.79 & -20.6604 \\
\hline 11 & 8 & 20 & 35 & 70 & 87.77 & 38.86692 & 0.64 & 3.876401 & 12.9 & -22.2118 \\
\hline 12 & 8 & 24 & 55 & 60 & 61.96 & 35.84223 & 0.59 & 4.58296 & 23.65 & -27.4766 \\
\hline 13 & 12 & 12 & 95 & 70 & 59.19 & 35.44497 & 0.76 & 2.383728 & 24.8 & -27.889 \\
\hline 14 & 12 & 16 & 75 & 60 & 55.92 & 34.95134 & 0.78 & 2.158108 & 31.47 & -29.9579 \\
\hline 15 & 12 & 20 & 55 & 90 & 113.66 & 41.11215 & 0.65 & 3.741733 & 14.25 & -23.0763 \\
\hline 16 & 12 & 24 & 35 & 80 & 81.07 & 38.1772 & 0.72 & 2.85335 & 14.35 & -23.137 \\
\hline
\end{tabular}

\section{Acknowledgement}

The authors would like to thank the management of Dr.M.G.R Educational and Research Institute for providing necessary support and encouragement. 


\section{References}

[1] P. Prasanna, Tallapragada V S S P Sashank, BhavirisettiManikanta andPruthviAluri, "Optimizing the process parameters of electrical dischargemachiningon AA7075 - SiCalloys", Materials Today: Proceedings., vol. 4, no. 8, (2017),pp. 8517-8527.

https://doi.org/10.1016/j.matpr.2017.07.198

[2] Xiaoming Yue, Xiaodong Yang, Jing Tian, Zhenfeng He andYunqing Fan,“Thermal, mechanical and chemical material removal mechanism ofcarbon fiber reinforced polymers in electrical discharge machining",International Journal of Machine Tools and Manufacture., vol.133, (2018),pp. 4-17.https://doi.org/10.1016/j.ijmachtools.2018.05.004

[3] K. Rajkumar,S. Santosh, S. Javed Syed Ibrahim and A.Gnanavelbabu, "Effect of electrical discharge machining parameters on microwaveheat treated Aluminium-Boron carbide-graphite composites",Procedia Engineering.,vol. 97, (2014),pp 1543-1550.

https://doi.org/10.1016/j.proeng.2014.12.438

[4] Md. Mofizul Islam, Chang Ping Li, Sung Jae Won and Tae Jo,"A Deburring strategy in drilled hole of CFRP composites usingEDM Process",Journal of Alloys and Compounds., vol. 703, (2017), pp. 477-485.https://doi.org/10.1016/j.jallcom.2017.02.001

[5]Nergiz Rona, Murat Yenisey, GokhanKucukturk, HakanGurun, Can Cogun andZiyaEsen, (2017) "Effect of electrical discharge machining on dental Y-TZPceramic-resin bonding",Journal of ProsthodonticResearch., vol. 6, no. 2, (2017), pp. 158-167. https://doi.org/10.1016/j.jpor.2016.07.006

[6] Vaibhav Gaikwad, S. VijayKumar and Jatti, "Optimization of material removal rate duringelectrical discharge machining of cryo-treatedNiTi alloys using Taguchi's method",Journal of King Saud University- Engineering Sciences., vol. 30, no. 3, (2018), pp.266-272. https://doi.org/10.1016/j.j.jksues.2016.04.003

[7]Anand Prakash Dwivedi andSounak Kumar Choudhury,"Increasing the performance of EDM process using tool rotation methodology for machining AISI D3 steel", Procedia CIRP., vol. 46, (2016), pp.131-134.https://doi.org/10.1016/j.procir.2016.03.207

[8]Martin Fides, PavolHvizdoš, Roman Bystrický, Alexandra Kovalčíková, Richard Sedlák, Jaroslav Sedláček and RóbertDžunda, (2017) "Microstructure, fracture, electrical properties and machinability of SiC-TiNbC Composites",Journal of the European CeramicSociety., vol. 37, no. 14, (2017), pp. 4315-4322.https://doi.org/10.1016/j.jeurceramsoc.2017.05.004

[9] Islam Shyha and Mark Rudd, (2016)"Electro-discharge machining of metal matrix composite materials",Advances in Materials and Processing Technologies, vol. 2, no. 2, (2016), pp.235-244. https://doi.org/10.1080/2374068x.2016.1164525

[10]A. Dey, S. Debnath and K.M. Pandey,"Optimization of electrical discharge machining process parameters for A16061/cenosphere composite using grey-based hybrid approach", Transactions of Nonferrous Metals Society of China., vol. 27, (2017), pp. 9981010.https://doi.org/10.1016/S1003-6326(17)60117-1 
[11] Philipp Ninz, Richard Landfried, Frank Kern and Rainer Gadow, "Electrical discharge machining of metal doped Y-TZP/TiC nanocomposites",Journal of the European Ceramic Society., vol. 35, (2015), pp.4031-4037.https://doi.org/10.1016/j.jeurceramsoc.2015.05.008

[12]M. Rozenek, J. Kozak,L. Dabrowski andK. Łubkowski, "Electrical discharge machining characteristics of metal matrix composites",Journalof Materials Processing Technology., vol. 109, no. 3, (2001), pp.367-370.https://doi.org/10.1016/s0924-0136(00)00823-2.

[13]A. Pramanik, (2014) "Developments in the non-traditional machining of particle reinforced metal matrix composites", International Journal of Machine Tool \& Manufacture., vol. 86, (2014), pp.44-61.https://doi.org/10.1016/j.ijmachtools.2014.07.003

[14]P. Narendra Singh, K. Raghukandan, M. Rathinasabapathi and B.C. Pai, "Electrical discharge machining of $\mathrm{Al}-10 \% \mathrm{SiC}_{\mathrm{p}}$ as-cast metal matrix composites",Journal of Materials Processing Technology., $\quad$ vol. $155-156, \quad$ (2004), 1657.https://doi.org/10.1016/j.jmatprotec.2004.04.321.

[15]N.V. Rengasamy, M. Rajkumar and S. Senthil Kumaran, (2016) "An analysis of mechanical properties and optimization of EDM process parameters of $\mathrm{Al} 4032$ alloy reinforced with $\mathrm{Zrb}_{2}$ and $\mathrm{Tib}_{2}$ in-situ composites", Journal of Alloys and Compounds., vol. 662, (2016), pp.325338.https://doi.org/10.1016/j.jallcom.2015.12.023

[16] GangdharuduTalla, Deepak Kumar Sahoo, S. Gangopadhyay andC.K. Biswas,"Modeling and multi - objective optimization of powder mixed electric discharge machining process Aluminum/Alumina metal matrix composite. Engineering Science and Technology", An International Journal., vol. $18, \quad$ no. $3, \quad$ (2015), pp.369373.https://doi.org/10.1016/j.jestch.2015.01.007

[17] Misbah Niamat, Shoaib Sarfraz, Haris Aziz, Mirza Jahanzaib, Essam Shehab, Wasim Ahmad and Salman Hussain, "Effect of different dielectrics on material removal rate, electrode wear rate and microstructures in EDM",Procedia CIRP., vol. 60, (2017), pp.27.https://doi.org/10.1016/j.procir.2017.02.02

[18]Bhaskar Chandra Kandpal, Jatinder Kumar and Hari Singh, "Optimisation of process parameters of electrical discharge machining of fabricated AA 6061/ $10 \% \mathrm{Al}_{2} \mathrm{O}_{3}$ aluminium based metal matrix composite", Materials Today: Proceedings., vol. 5, no. 2, (2018), pp.44134420.https://doi.org/10.1016/j.matpr.2017.12.009

[19]Xue-Cheng Xi, Mo Chen and Wan-Sheng Zhao, (2017) "Improving electrical discharge machining efficiency by using a Kalman Filter for estimating the gap voltages",Precision Engineering., vol. 47, (2017), pp.182-190.https://doi.org/10.1016/j.precisioneng.2016.08.003

[20]R. Landfried, F. Kern and R. Gadow, (2015)"Electrically conductive ZTA-TiC Ceramics: Influence of $\mathrm{TiC}$ particle size on material properties and electrical discharge machining", International Journal ofRefractory Metals and Hard Materials., vol.49, (2015), pp.334338.https://doi.org/10.1016/j.ijrmhm.2014.08.003

[21] Mayu Shinohara and Masanori Kunieda,"Influences of discharge current pulse shape on machining characteristics in EDM", Procedia CIRP., vol. 95, (2020), pp. $200-203$. https://doi.org/10.1016/j.procir.2020.03.146 
[22]Shirsendu Das, Swarup Paul and BiswanathDoloi, "A gap-active electrical discharge machining (GA-EDM) to rectify the textural defects of the processed surface", Journal of Manufacturing Processes., vol. 64, (2021), pp.594-605.

https://doi.org/10.1016/j.jmapro.2021.01.053

[23] Shirsendu Das, Uttam Acharya, S.V.V.N. Siva Rao, Swarup Paul andBarnikSaha Roy, "Assessment of the surface characteristics of aerospace grade AA6092/ 17.5 SiCp-T6 composite processed through EDM",CIRP Journal of Manufacturing Science and Technology., vol. 33, (2021), pp.123-132.https://doi.org/10.1016/j.cirpj.2021.03.005.

[24]Hardeep Singh, Jujhar Singh, Shubham Sharma andJasgurpreet Singh Chohan, "Parametric optimization of MRR \& TWR of the Al6061/SiC MMCsprocessed during die-sinking EDM using different electrodes", Materials Today:Proceedings. In press (2021). https://doi.org/10.1016/j.matpr.2021.06.323

[25] Huu-Phan Nguyen, Ngoc-Vu Ngo and Quoc-Tuan Nguyen, "Optimizing process parameters in EDM using low frequency vibration for materialremoval rate and surface roughness", Journal of King Saud University - Engineering Sciences., vol.33, no. 4, (2021), pp. 284-291. https://doi.org/10.1016/j.jksues.2020.05.002 